\author{
Dariusz POROS ${ }^{1^{*}}$ \\ Magdalena WISNIEWSKA ${ }^{1}$ \\ Stanislaw ZABORSKI ${ }^{1}$
}

\title{
COMPARATIVE ANALYSIS OF WEDM WITH DIFFERENT WIRE ELECTRODES APPLIED TO CUT TITANIUM Ti6AI4V
}

\begin{abstract}
The machining of titanium alloys by traditional methods causes many disadvantages of both technical and economic nature. These materials are characterized by very low thermal conductivity and belong to hard to machine materials. When machining these materials with conventional methods, there is a problem of chips thermal softening and increased tool wear. During machining, e.g. milling despite intensive cooling, the performance achieved is low. Although traditional processes of titanium alloys treatment pose many problems, the use of this strong and lightweight materials is still evolving. The aim of this article was to present the issue of wire electrical discharge machining of Titanium alloy Ti6Al4V. In particular, the comparison of brass wire and non-consumable molybdenum electrode and flushing techniques were analyzed. The relationship between the overheating of the machined surface layer and the magnitude of stresses and the formation of micro cracks on the machined surface was discussed. Based on its own research and the presented analysis of the literature on the subject, future directions of further research were indicated. An attempt should be made to investigate how flushing efficiency affects the machined shape, structural changes and chemical composition of the titanium alloy's surface layer.
\end{abstract}

\section{INTRODUCTION}

WEDM (Wire Electrical Discharge Machining) is an alternative shaping route for manufacturing complex component shapes of hard to machine and brittle materials. WEDM assures high machining efficiency, low cost of tooling and virtually no deformation induced into a thin-walled or slender workpiece. There are lots of models describing WEDM. Most authors analyse surface layer state of such materials like titanium alloys which are increasingly used in aerospace or automotive industries. Titanium is also commonly applied as medical implant material in a wide variety of applications. Unfortunately, the low thermal conductivity, as well as the ability to hardening as a result of the temperature increase, are a problem during cutting. Therefore, in the pursuit of optimizing the machining costs and efficiency while maintaining the desired dimensional accuracy of the titanium

\footnotetext{
${ }^{1}$ Mechanical Engineering, Wroclaw University of Science and Technology, Wroclaw, Poland

* E-mail: dariusz.poros@pwr.edu.pl https://doi.org/10.36897/jme/130399
} 
alloy elements for their shaping, electrical discharge machining is often used. In this work, the results of wire WEDM of Ti6Al4V are collated by cutting with consumable brass and non-consumable molybdenum wire. The electrode is $\mathrm{CuZn} 37$ brass wire with a diameter of $0.25 \mathrm{~mm}$ which is used only once. Second wire electrode is popular molybdenum wire with a diameter of $0.18 \mathrm{~mm}$. The aim of the article was to prove whether WEDM with a non-consumable electrode is a viable alternative to brass electrode wire cutting of titanium alloys. The analysis of 3D geometry of the Ti6A14V alloy surface after WEDM is presented. The possibilities and limitations of WEDM machining of titanium alloys were indicated.

\section{WEDM OF TITANIUM ALLOYS}

Titanium alloys are classified into groups based on their structure and predominant phase at room temperature. The types of alloys include alpha structure, (alpha + beta) + alpha structure. In alloys resistant to higher temperatures (700-800 degrees) with aluminides (alpha phase, gamma phase). The Titanium alloys due to their strength properties, resistance to corrosive and aggressive biological environments, is a material commonly used in a wide range of applications. There is still space to explore how the material of proper wire electrode and application of time parameters for WEDM of titanium alloys affects the surface roughness, structure, the stresses and the chemical composition of the formed surface layer. Problems of electrical discharge machining of titanium alloys were successfully undertaken, among others, and still is the actual subject of many studies. It is worth to notice that different materials of the wire electrode can significantly influence the stress state in the surface layer after WEDM. The use of coated electrodes changes the amount of stresses in the material after WEDM. The authors [1] used three different electrodes: solid brass $\mathrm{CuZn} 37$ and copper electrodes coated with one or two zinc layers. With the appropriate values of the discharge current and the pulse time, it was possible to reduce the magnitude of stresses in the surface layer. Even compressive stresses were obtained on the surface after treatment with the CuZn37 electrode. An effective method of reducing the negative impact of surface stress on the properties of the workpiece is stress relaxation through appropriate heat treatment [2]. The conducted research on the removal of the heat-affected layer in a subsequent number of passes during cutting, confirms the possibility of a significant reduction of the HAZ (Heat Affected Zone) depth. A significant reduction was achieved after just three passes [3]. In [4] authors observed that from among employed wire electrodes more uniform surface characteristics specimen of Ti6Al4V were obtained by applying zinc-coated electrode instead of uncoated brass CuZn37 wire. WEDM parameter optimization was also studied. The parameters of WEDM have a great influence on the thickness and chemical content of the titanium oxide layer constituted on the machined surface. The analyzed parameters were variables such as time between two pulses, pulse duration, flushing pressure, wire speed and wire tension, which have more influence on the surface characteristics. The time between two pulses occurred the most influential parameter. The work [5] Sarkar proposes a method of optimizing the WEDM parameters of titanium- $\gamma$ alloys using the Taguchi control method, Innova variance and Pareto optimization. The aim of the research was to determine the appropriate parameters 
of WEDM due to the obtained surface roughness and dimensional and shape accuracy. As the conclusion of the experiment, the discharge time was established as having the most influence on the surface roughness of machined titanium alloy. Dimensional accuracy was the most sensitive effect. All of the analysed variable parameters had an important impact on accuracy. The most significant parameter was operating voltage. The cutting speed depends primarily on the value of the pulse times and the pause between pulses. It has been shown that in the case of titanium machining, the pause time does not significantly affect the surface roughness and the accuracy of the process. Such a situation allows choosing this parameter to stabilize the process (de-ionization of the inter-electrode gap) without reducing the quality or accuracy of the process. Authors [6] stated that improper electrical parameters settings can affect the processing efficiency and surface roughness due to the arcing phenomenon that leads by discharge point of focus. The objective of the paper is to uncover the influence of three different machine rates which are $2 \mathrm{~mm} / \mathrm{min}, 4 \mathrm{~mm} / \mathrm{min}$ and $6 \mathrm{~mm} / \mathrm{min}$ with constant current $(6 \mathrm{~A})$ with WEDM of Titanium Ti-6Al-4V. The effects of different process parameters on the kerf width, MRR, surface roughness and surface topography are also discussed. The best combination of machining parameter viz. machine feed rate $(4 \mathrm{~mm} / \mathrm{min})$, wire speed $(8 \mathrm{~m} / \mathrm{min})$, wire tension $(1.4 \mathrm{~kg})$ and voltage $(60 \mathrm{~V})$ were identified. The paper highlights the importance of process parameters and different machining conditions on kerf width, MRR, surface roughness $(R a)$ and surface topography. In similar tests, the use of high energy discharges accelerates the cutting process, but the long pulse time and high discharge current contribute to the formation of high residual stresses in the surface layer [7].

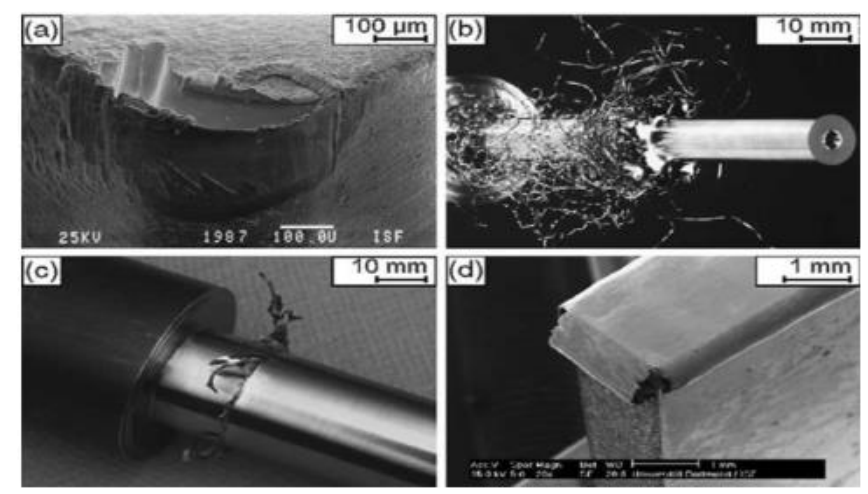

Fig. 1. Problems occurring during traditional cutting processes of Ti6Al4V a) increased tool wear, b) undesirable chip types, c) thermal marks after turning and d) grinding [8]

\section{THE INVESTIGATION METHOD}

Wire electrical discharge machines are classified into two different wire feed speed types. First CNC low-speed feed wire cut EDM machine with consumable brass electrodes and second CNC high-speed feed wire cut EDM machine usually with a non-consumable electrode. This classification method is widely accepted in the market. CNC high-speed feed wire cut EDM machine, see Fig. 2, its electrode wire feeds reciprocally at a fast speed, 
regularly $4-11 \mathrm{~m} / \mathrm{s}$, and the electrode is used reciprocally. But fast feed speed of electrode wire will cause vibration and interval stop of direction change, machine quality goes down. High feed speed wire cut EDM machine is original from China, and widely used in the domestic market. Nowadays, many China-made high-speed feed wire cut EDM machines have the ability of multi-time cutting, which is unique for low-speed feed wire cut EDM machine before, with multi-time cutting ability, the surface finish had been improved apparently, up to around $1 \mu \mathrm{m}$.
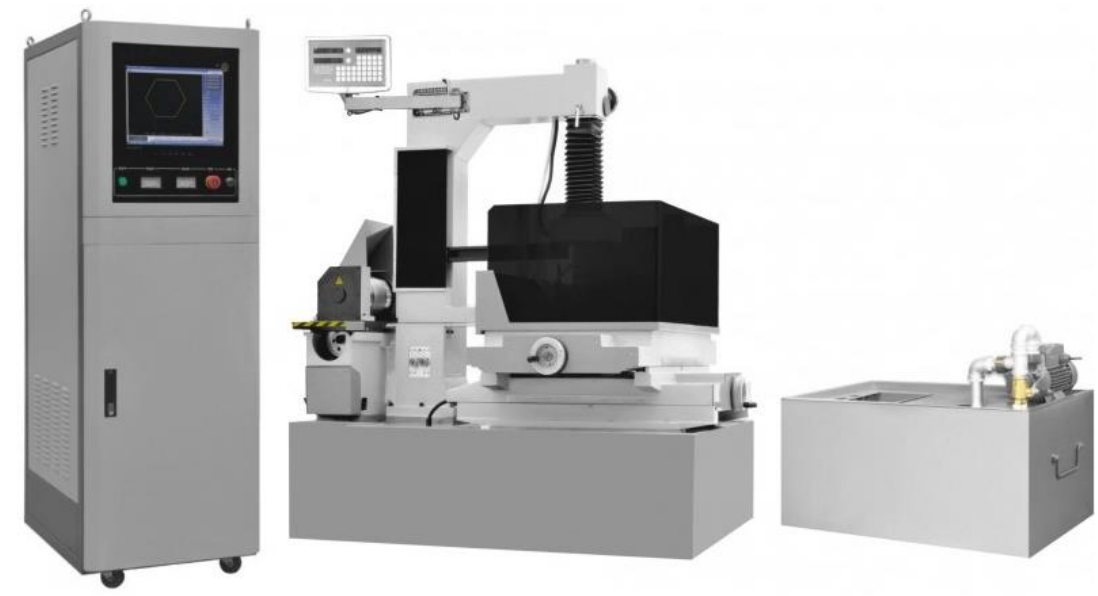

Fig. 2. Non-consumable, molybdenum wire, high feed type WED machine DK7750A

CNC low-speed feed wire cut EDM machine, see Fig. 3, its electrode wire feeds slowly and continuously to one direction, regularly $0.2 \mathrm{~m} / \mathrm{s}$, electrode won't be used again after electrical discharging, work smoothly, evenly, less vibration, cutting quality is pretty good, such wire cut EDMs are mainly produced in Japan, Switzerland, etc. CNC low-speed feed wire cut EDMs are mainly used for machining products with a very strict requirement of accuracy and surface finish.

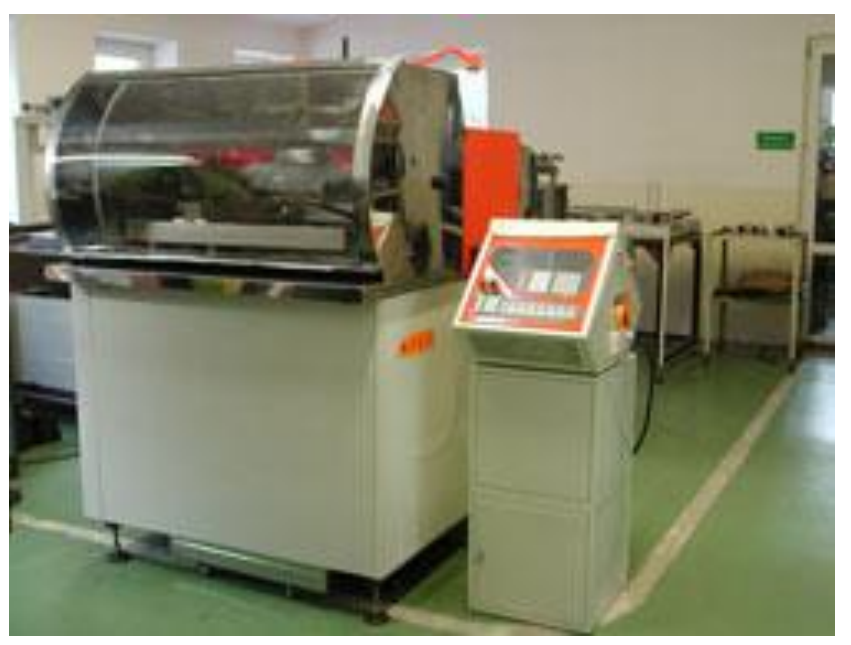

Fig. 3. Brass consumable electrode, low feed type WED machine ZAP BP12dk 
Objectives of the study required a three-stage study:

- the wire EDM process was modelled by using an experiment design and a response surface for the central composite one [9]. The effects of pulse time parameters (ON, $\mathrm{OFF})$ were tested on the MRR and the surface roughness $(R a)$ for both types of machines and electrodes,

- HAZ (Heat Affected Zone) was analyzed on scanning electron microscopy images,

- graphical presentation and analysis of the results was presented.

\section{EXPERIMENTAL PROCEDURE AND RESULTS}

The test piece geometry is shown in Fig. 4. Cut out in the process were parallelepipeds $5 \times 20 \times 30 \mathrm{~mm}$. Two types of wires were applied. A first consumable electrode made of brass $\mathrm{CuZn} 37$ with a diameter of $0.25 \mathrm{~mm}$ and strength $900 \mathrm{MPa}$. Second in the fixed diameter of $0.18 \mathrm{~mm}$ to meet blueprint requirements of narrow kerfs and near-sharp, inside corner radii. This $0.18 \mathrm{~mm}$ of diameter gives a perfect balance between lifetime, cutting speed, cutting tolerances and surface quality. Because of its high tensile strength, molybdenum electrode aids in maintaining excellent wall straightness and reducing the number of wirebreaks common with brass wires. In special cases, typically in medical and military applications, there can be no copper or zinc contamination on the wire cut surface. These criteria eliminate all brass/copper-family wires and force the use of a molybdenum wire. In contradiction to brass wires $\left(480 \mathrm{~N} / \mathrm{mm}^{2}\right)$, molybdenum wire is a very high strength wire (tensile strength $1830 \mathrm{~N} / \mathrm{mm}^{2}$ ). The specification of the electrodes used in the present study is given in Table 1.

Table 1. Physical and thermos - physical properties of the material of applied wire electrodes

\begin{tabular}{|l|c|c|}
\hline $\begin{array}{l}\text { Material: } \\
\text { Properties: }\end{array}$ & $\mathrm{CuZn37}$ & Molybdenum \\
\hline Melt. point, [K] & 1183 & 2895 \\
\hline Thermal conductivity, $\left[\frac{\mathrm{kg} \times m}{s^{3} \times K}\right]$ & 115 & 138 \\
\hline Electrical conductivity, $\left[\frac{s^{3} \times A^{2}}{k g \times m^{3}}\right]$ & $16.2 \times 10^{6}$ & $18.7 \times 10^{6}$ \\
\hline \multicolumn{1}{|c|}{$\mathrm{kg}^{3}$} & 8400 & 10220 \\
\hline Tensile strength, [MPa] & 480 & 1830 \\
\hline Thermal expansion coefficient $\left[\mathrm{K}^{-1}\right]$ & $21 \times 10^{6}$ & $4.8 \times 10^{6}$ \\
\hline
\end{tabular}

Workpiece material Ti6Al4V is an alpha-beta structure titanium alloy. Due to a high strength-to-weight ratio and excellent corrosion resistance is one of the most commonly used titanium alloys. This popular titanium alloy is applied in a wide range of applications 
where low density and excellent corrosion resistance are necessary such as e.g. planes, aerospace, sports equipment industry, marine industry and biomechanical applications (implants and prostheses). More physical properties of workpiece material, are described in Table 2.

Table 2. Properties of machined workpiece material

\begin{tabular}{|l|c|}
\multicolumn{1}{|c|}{ Physical properties of Ti6Al4V } & \multicolumn{1}{|c|}{} \\
\hline Density, $\left[\mathrm{g} / \mathrm{cm}^{3}\right.$ ] & 4.42 \\
\hline Melting range, $\left[{ }^{\circ} \mathrm{C}\right]$ & 1649 \\
\hline Specific heat, $\left[\mathrm{J} / \mathrm{kg}{ }^{\circ} \mathrm{C}\right]$ & 560 \\
\hline Volume electrical resistivity, [ohm cm] & 170 \\
\hline Thermal conductivity, [W/m K] & 7.2 \\
\hline Tensile strength, [MPa] & 1000 \\
\hline Elastic modulus, [GPa] & 114 \\
\hline Hardness, [Rockwell C] & 36 \\
\hline
\end{tabular}

The height of the cut workpieces was $5 \mathrm{~mm}$ for both used wire electrodes. The surface roughness was measured using a Rank Taylor Hobson - Taly form Series 120 L profilegraphometer. The $R a$ parameter of roughness was chosen as a representative measure of surface finish. Three specimens were taken for each value of the process parameters. For depth of HAZ analysis scanning electron microscopy images were used.

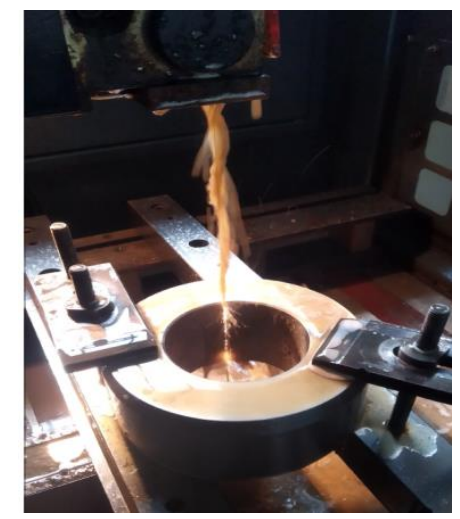

Fig. 4. Workpiece attached to the table of a wire electrical discharge machine DK7750A

\section{EFFICIENCY OF THE PROCESS}

The WEDM MRR (Material Removal Rate) was determined as a product of cutting rate and workpiece thickness. The dependence of area efficiency on time parameters obtained through regression analysis is shown in Fig. 5. Longer times of discharges and/or shorter time gaps between pulses resulted in better efficiency of cutting with a brass electrode. Similar results were reported in papers $[1,5]$. It was also found that longer time 
gaps between pulses had a beneficial effect on the stability of the operation without compromising efficiency [5]. WEDM with molybdenum electrode was realized with longer pulses and much longer breaks. Sum of energy transformed to discharges was greater than for brass electrode. But one of the disadvantages of high-temperature resistance is that the spark craters made in the molybdenum wire electrode are much smaller than the ones made in the brass. A small volume of craters and an inter-electrodes gap is low effective for flushing process. But when discharge on time is too long there is a smaller number of effective discharges because of an increased amount of debris inside the gap.

a)

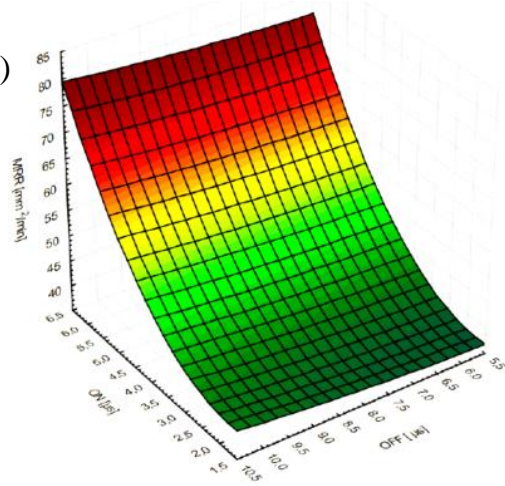

b)

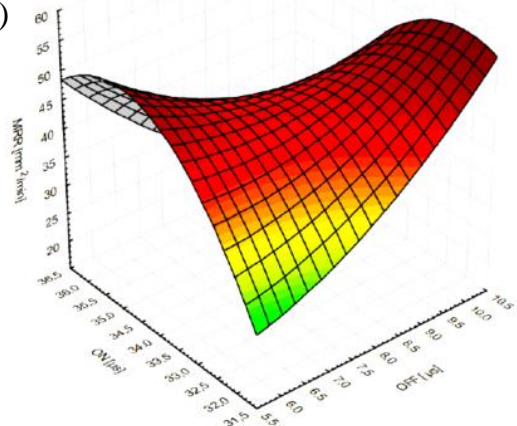

Fig. 5. Influence of time-based parameters of WEDM on electrical discharge cutting efficiency of Ti6Al4V: a) brass wire, b) molybdenum wire

\section{SURFACE ROUGHNESS}

The dependence of surface roughness $R z$ upon ON/OFF times was found to follow patterns shown in Fig. 6. Higher discharge times resulted in worse finish regardless of the tool material. The effect of time between two pulses on $R a$ is less pronounced for both electrode types, but longer OFF periods make for improved stability of the process. What is worth mentioning that roughness for WEDM with molybdenum electrode again fast reaches the limit and speed of creating craters decrease with longer discharge time. Again for higher energy discharges, there is not enough effective inter-electrode gap flushing.

a)

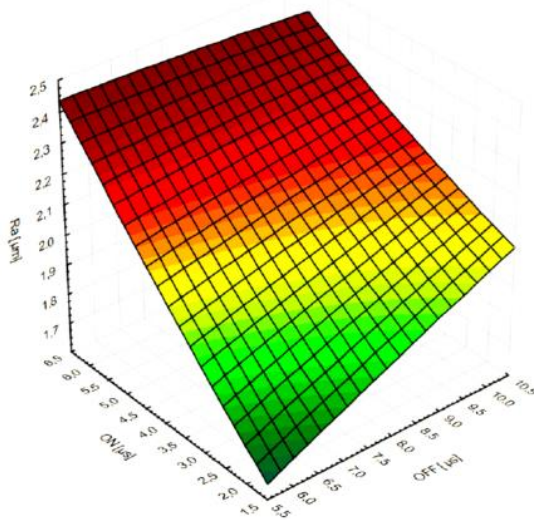

b)

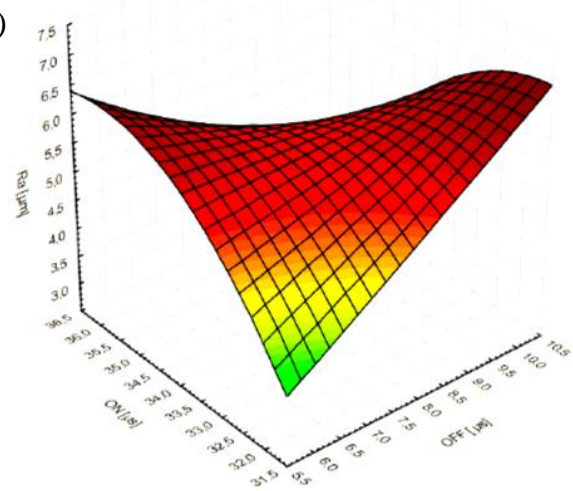

Fig. 6. The influence of time-based parameters of WEDM on surface roughness of Ti6Al4V: a) brass wire, b) molybdenum wire 


\section{STATE OF THE HEAT AFFECTED LAYER}

Conditions during electro erosion process favor the formation of HAZ (Heat Affected Zone). Surface images after WEDM of the tested titanium alloy with visible numerous micro-craters are introduced in Fig. 7. The heat-affected zone reaching deep into the material must be minimized because - although in some applications it is not a problem - it has usually changed its structure and properties, e.g. increased hardness. As a more fragile, hardened layer it may initiate micro-cracks to deepen. It was important to analyze the possibilities of HAZ elimination to reduce residual stresses and avoid the risk of failure. High temperature and rapid cooling of the surface causes an unequal temperature distribution between the material layers. After processing, the stresses remain in the material, which can be tensile or compressive. Usually, these are tensile stresses that are undesirable due to the decreasing impact on the mechanical properties of the material. As a result of the analysis of the depth of the thermally changed layer, it was possible to demonstrate both the effectiveness of using a consumable brass electrode and the ability to reduce the HAZ by choosing the right time parameters to avoid overheating of the surface. Cutting with molybdenum was more energy and higher temperature but worse flushing and effectiveness was lower than for brass The measurements showed that the average HAZ depth after cutting with a molybdenum electrode is $25 \mu \mathrm{m}$ after the rough pass, accordingly.
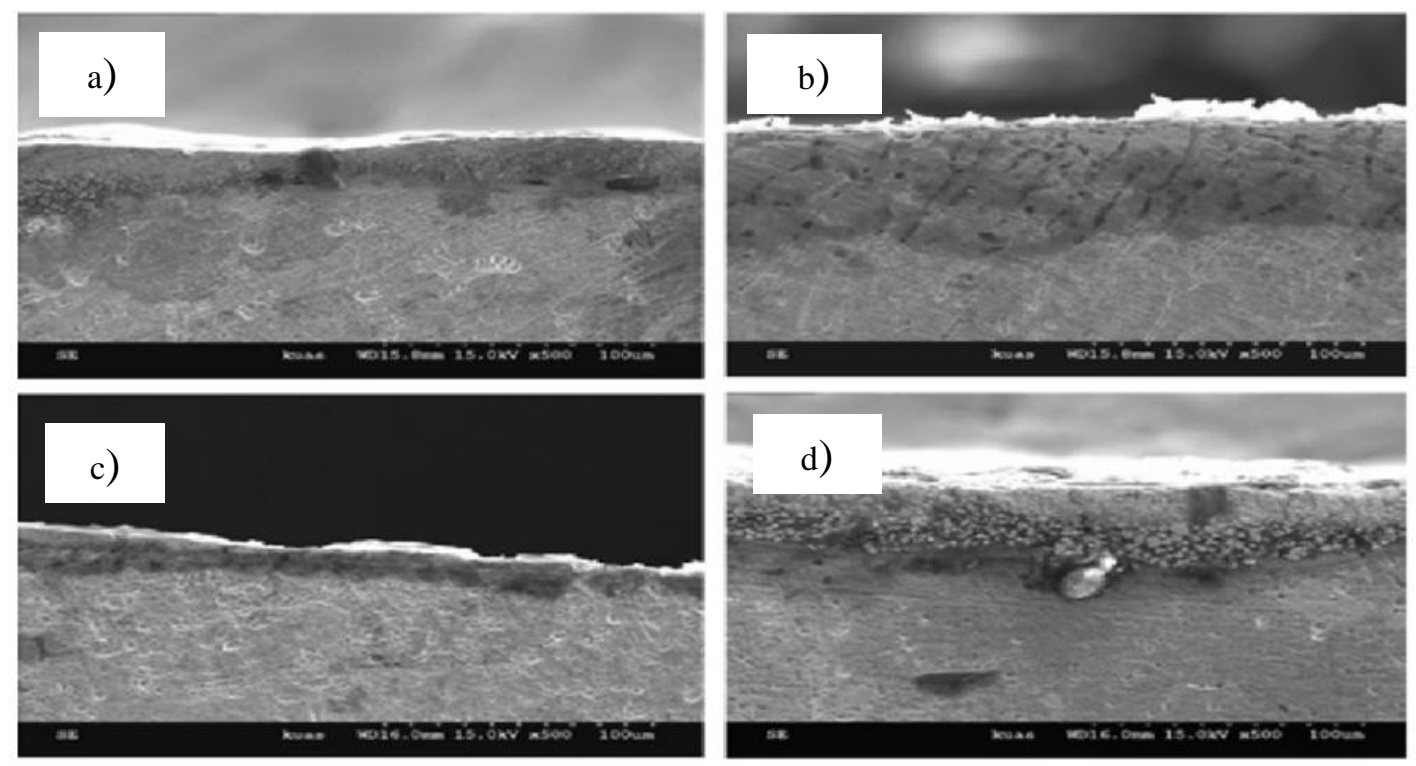

Fig. 7. The heat-affected layer of machined Ti6Al4V: a) molybdenum finish cutting,

b) molybdenum rough cutting, c) brass finish cutting, d) brass rough cutting

The use of a brass electrode allowed to reduce the HAZ depth to $15 \mu \mathrm{m}$ after the rough cut. Reduced heat-affected zone is exposed in Fig. 7. WEDM parameters for both cutting tests were optimized to obtain the best MRR. Current and time parameters defining the amount of energy transferred to the inter-electrode gap were much higher for molybdenum wire. Also, off time has to be increased to pull out the burned away carbonized particles 
between wire and workpiece. This is less effective to pull out the debris of the cutting area because of the smaller craters in the wire. The temperature in the inter-electrode gap due to worse flushing (less cooling) supposed to be higher and affect deeper into the material.

Brass wire electrodes are the combination of zinc, low melting point $\left(420^{\circ} \mathrm{C}\right)$ and high sublimation pressure, with copper $\left(1080^{\circ} \mathrm{C}\right)$ in the $\mathrm{CuZn} 37$ alloy. The authors attribute the effect of HAZ reduction to the action of zinc vapor to limit heat transfer. The zinc from the external surface sublimates, which reduces the number of particles released into the gap. Instead of molten metal particles and evaporating dielectric, the gap is largely filled with a gas of zinc. This gas has the lower thermal conductivity lower than e.g. molten copper. This allows limiting the penetration of heat into the workpiece [10].

\section{CONCLUSIONS}

The presented investigation on WEDM of Ti6Al4V proved that time parameters of the WEDM process have a significant effect on manufacturing outcome characteristics. Wire electrode material can significantly affect WEDM effects. Molybdenum wire resists to very high pulling forces and breaking it is very difficult. Non-consumable molybdenum electrodes are an economical very interesting high functional tool able to make high-quality parts and savings in production cost. The conducted research enables the following conclusions to be drawn:

- Experiments confirmed the advantage of cutting with a brass electrode over the WEDM efficiency with molybdenum wire. It was possible to cut the workpiece $71 \%$ faster with a brass electrode.

- For both types of electrodes higher times between discharges were found to increase the stability of the operation without markedly compromising efficiency.

- Longer discharge time did increase efficiency but provokes worse roughness indexes for both types of electrodes. Minimum roughness obtained was for brass electrode and it was nearly twice lower compared to molybdenum wire.

- Because molybdenum wire has very high melting temperature, $\left(2625^{\circ} \mathrm{C}\right)$, compared to brass $\left(900-940^{\circ} \mathrm{C}\right)$. The molybdenum electrode can handle very high working temperatures but WEDM resulted in deep HAZ $(25 \mu \mathrm{m})$. For comparison with sublimated zinc for brass wire reduced HAZ depth $(15 \mu \mathrm{m})$ with the same or higher cutting speed as for molybdenum electrode.

- Due to the higher pulling forces for molybdenum wire it should be possible to increase flushing efficiency by the faster move through a workpiece. Then wire takes much more carbonized particle with him and cutting is faster. Improved flushing with a slightly longer retract time is here the solution.

- The EDM craters left on the molybdenum wire's surface are very small compared to those left on the brass. So, the wire is almost not damaged after passing through the material and this results in a much longer of reusing the wire. The lifetime of the molybdenum wire can reach sometimes weeks.

- It is also important to analyse the impact of WEDM parameters on the condition of the surface layer, such as internal stresses and fatigue strength in further research. 


\section{REFERENCES}

[1] ANTAR M.T., SOO S.L., ASPINWALL D.K., JONES D., PEREZ R., 2011, Productivity and Workpiece Surface Integrity When WEDM Aerospace Alloys Using Coated Wires, Procedia Engineering, 19, 3-8.

[2] STRASKY P., JANECEK J., HARCUBA M., BUKOVINA M., WAGNER L., 2011, The Effect of Microstructure on Fatigue Performance of Ti-6Al-4V Alloy After EDM Surface Treatment for Application in Orthopedics, Journal of the Mathematical Behavior of Biomedical Materials, 4/8, 1955-1962.

[3] ASPINWALL D.K., SOO S.L., BERRISFORD A.E., WALDER G., 2008, Workpiece Surface Roughness and Integrity After WEDM of Ti-6Al-4V and Inconel 718 Using Minimum Damage Generator Technology, CIRP Annals - Manufacturing Technology, 57, 187-190.

[4] KURIAKOSE S., SHUNMUGAM M.S., 2004, Characteristics of Wire-Electro Discharge Machined Ti-6A1-4V Surface, Materials Letters, 58/17-18, 2231-2237.

[5] SARKAR S., MIITRA S., BHATTACHARYYA B., 2005, Parametric Analysis and Optimization of Wire Electrical Discharge Machining of Gamma-Titanium Aluminide Alloy, Journal of Materials Processing Technology, 159, 286-294.

[6] ALIASA A., ABDULlAHA B., MOHD A., 2012, Influence of Machine Feed Rate in WEDM of Titanium Ti-6A1-4V with Constant Current (6A) Using Brass Wire, Procedia Engineering, 41, 1806-1811.

[7] YADAV V., JAIN V.K., DIXIT P.M., 2002, Thermal Stresses Due to Electrical Discharge Machining, International Journal of Machine Tools \& Manufacture, 42/8, 877-888.

[8] WEINERT K., PETZOLDT V., 2004, Machining of NiTi Based Shape Memory Alloys, Materials Science and Engineering, 378/1-2, 180-184.

[9] CHEN S.L., YAN B.H., HUANG F.Y., 1997, Influence of Kerosene and Distilled Water As Dielectrics on the Electric Discharge Machining Characteristics of Ti-6A1-4V, J. Mat Proc. Technology 87, 107-111.

[10] POROŚ D., ZABORSKI S., 2009, Semi-Empirical Model of Efficiency of Wire Electric Discharge Machining of Hard-to-Machine Materials, J. Mat. Proc. Technology, 209/3, 1247-1253. 